\title{
The octarepeat region of prion protein, but not the TM1 domain, is important for the antioxidant effect of prion protein
}

\author{
Muriel Malaisé $^{\mathrm{a}}$, Hermann M. Schätzl ${ }^{\mathrm{b}}$, Alexander Bürkle ${ }^{\mathrm{a}, *}$ \\ a Molecular Toxicology Group, Department of Biology, University of Konstanz, Box X911, D-78457 Konstanz, Germany \\ ${ }^{b}$ Institute of Virology, Prion Research Group, Technical University Munich, D-81675 Munich, Germany
}

Keywords:

Antioxidant

Prion protein

Copper

Signaling

ROS detection

Mitochondrial membrane potential

\begin{abstract}
A B S T R A C T
The cellular prion protein $\left(\mathrm{PrP}^{c}\right)$ plays a crucial role in the pathogenesis of prion diseases, but its physiological function is far from understood. Several candidate functions have been proposed including binding and internalization of metal ions, a superoxide dismutase-like activity, regulation of cellular antioxidant activities, and signal transduction. The transmembrane (TM1) region of $\operatorname{PrP}^{c}$ (residues 110-135) is particularly interesting because of its very high evolutionary conservation. We investigated a possible role of TM1 in the antioxidant defense, by assessing the impact of overexpressing wt-PrP or deletion mutants in $\mathrm{N}_{2} \mathrm{~A}$ mouse neuroblastoma cells on intracellular reactive oxygen species (ROS) levels. Under conditions of oxidative stress, intracellular ROS levels were significantly lowered in cells overexpressing either wild-type PrPc (wt$\mathrm{PrP}$ ) or a deletion mutant affecting TM1 ( $\triangle 8 \mathrm{TM} 1-\mathrm{PrP})$, but, as expected, not in cultures overexpressing a deletion mutant lacking the octapeptide region ( $\triangle$ octa-PrP). Overexpression of wt-PrP, $\triangle 8 T M 1-P r P$, or $\triangle$ octaPrP did not affect basal ROS levels. Interestingly, the mitochondrial membrane potential was significantly lowered in $\triangle$ octa-PrP-transfected cultures in the absence of oxidative stress. We conclude that the protective effect of $\operatorname{PrP}^{\mathrm{C}}$ against oxidative stress involves the octarepeat region but not the TM1 domain nor the highaffinity copper binding site described for human residues His $96 / \mathrm{His} 111$.
\end{abstract}

\section{Introduction}

Transmissible spongiform encephalopathies (TSEs), also termed prion diseases, are neurodegenerative lethal diseases occurring in various mammalian species [1,2]. TSEs are characterized by spongiform change, neuronal death, astrogliosis, and accumulation of a disease-associated, pathogenic isoform of prion protein (PrP), termed $\operatorname{Pr}^{\mathrm{Sc}}$, which arises from a normal cellular isoform, termed $\operatorname{Pr}^{c}$, in a posttranslational process involving refolding [3]. $\operatorname{Pr}^{c}$ is encoded by the PRNP gene on human chromosome 20 and mouse chromosome 2 $[4,5]$. This gene is highly conserved during evolution [6-8]. The $\operatorname{PrP}^{c}$ protein contains a long flexible amino terminal tail (amino acids [aa] 23-128) followed by three $\alpha$-helices and two $\beta$-sheets [9]. $\operatorname{PrP}^{c}$ contains an octarepeat region (amino acids 51-91) and a highly hydrophobic region also called transmembrane domain 1 (TM1) (aa

Abbreviations: $\triangle \Psi$, mitochondrial membrane potential; BSO, buthionine sulfoximine; DMEM, Dulbecco's modified Eagle's medium; FACS, fluorescence-activated cell sorting; FCS, fetal calf serum; GPI, glycosyl-phosphatidyl-inositol; $\mathrm{H}_{2} \mathrm{DCFDA}, 2^{\prime}, 7^{\prime}$ dichlorohydrofluorescein diacetate; $\mathrm{N}_{2} \mathrm{~A}$, mouse neuroblastoma cells; PBS, phosphatebuffered saline; PrP, prion protein; ROS, reactive oxygen species; RT, room temperature; SOD, superoxide dismutase; $\mathrm{tBOOH}$, tert-butylhydroperoxide; TM, transmembrane; TMRE, tetramethylrhodamine ethyl ester perchlorate; TSE, transmissible spongiform encephalopathies.

* Corresponding author. Fax: +497531 884033.

E-mail address: alexander.buerkle@uni-konstanz.de (A. Bürkle).
110-135). PrP $^{c}$ can be glycosylated on Asn 180 and Asn196 and comprises a disulfide bridge between Cys 178 and Cys213. $\operatorname{PrP}^{c}$ is a glycosyl-phosphatidyl-inositol (GPI)-linked glycoprotein and is enriched in detergent-resistant membranes. The very high degree of conservation of the TM1 region is indicative of an essential contribution to the physiological function of $\mathrm{PrP}^{c}$. This region extends from aa 110 through 135 and comprises an array of hydrophobic amino acids. It is also a highly flexible and unstructured portion of $\operatorname{Pr} \mathrm{P}^{\mathrm{C}}$ as shown by NMR analysis of recombinant $\operatorname{PrP}[9]$.

Previously we have shown that expression of a deletion mutant of 8 aa in the TM1 domain (PrP $\Delta 114-121)$ is sufficient to inhibit $\operatorname{PrP}^{\mathrm{Sc}}$ accumulation in prion-infected neuroblastoma cells in a transdominant fashion [10]. Recently, we generated transgenic mice expressing the same deletion mutant [11]. These mice (termed PrP $\Delta_{\mathrm{pHC}}$ in Ref. [11]) did not show any obvious spontaneous phenotype. However, crossing PrP $\Delta_{\mathrm{pHC}}$ mice on a Prnp ${ }^{-/-}$background with transgenic mice carrying pathogenic $\operatorname{PrP} \Delta 94-134$ or $\operatorname{PrP} \Delta 32-134$ transgenes ("Shmerling mice") led to enhanced pathogenicity of the $\operatorname{PrP}$ 494-134 transgene whereas pathogenicity of PrP $\Delta 32-134$ was diminished [11].

Apart from the above effects concerning prion propagation and modulation of the "Shmerling syndrome," a variety of other putative functions have been proposed for $\operatorname{PrP}^{c}$. These include immunoregulation [12,13], signal transduction [12,14-16], binding of copper and other metals and their sequestration [17-20], synaptic transmission 
[21], induction of or protection against apoptosis [22-24], superoxide dismutase (SOD)-like activity [25-27], and regulation of cellular antioxidant activities $[28,29]$. The ability of $\operatorname{Pr}^{c}$ to bind copper via its octarepeat region and via two independent histidine residues (human residues His 96 and His111 [corresponding to murine residues 95 and 110]) $[30,31]$ might play an important role in $\operatorname{Pr} P^{c}$ function(s). $\operatorname{Pr} P^{c}$ could act as a sensor for oxidative stress [29,32-34], and trigger intracellular anti-stress signaling events. As to the proposed SOD-like activity of $\operatorname{PrP}^{c}[25,26,35]$, it should be noted that other groups either have been unable to confirm this [27] or have proposed some indirect mechanism [36]. Interestingly recent work on stroke models has associated $\operatorname{Pr}^{c}$ with a protective function [37-41], which may well be related with the above-noted antioxidant activity.

Intriguingly there exists a clear link between transition-metal binding and neurodegenerative diseases, including prion diseases [42]. In some paradigms transition metal binding seems to protect against oxidation, in others to enhance it by disturbing free radical homeostasis $[43,44]$.

The mitochondrial membrane potential $(\Delta \Psi)$ arises from proton translocation from the mitochondrial matrix to the mitochondrial intermembrane space through the electron transport chain. $\Delta \Psi$ reflects the mitochondrial activity of the cell. The major mitochondrial activity is, of course, ATP production, but mitochondria can also generate ROS by occasional escape of electrons from the respiratory chain. Hyperpolarization of the inner mitochondrial membrane (i.e., increased $\Delta \Psi$ ) is known to facilitate ROS production, which in turn induces a decrease of $\Delta \Psi$ via the induction of uncoupling protein 2 (UCP2). Uncoupling proteins allow passage of protons through the inner mitochondrial membrane without ATP production, which leads to both deficiency in ATP formation and immediate lowering of mitochondrial production of ROS. The biological importance of this mechanism is highlighted by the fact that persistent overproduction of ROS will lead to calcium influx and cytochrome $c$ release into the cytoplasm, thus triggering apoptosis $[45,46]$. Based on this knowledge it was interesting to study if the antioxidant effect of $\operatorname{PrP}^{c}$ is mediated by modulation of $\Delta \Psi$ and if TM1 plays a role in such an effect. It should be noted that previous publications from the literature have reported conflicting results as to the role of $\operatorname{PrP}^{c}$ on mitochondrial respiratory function $[47-49]$ and therefore the situation was unclear.

The aim of the present study was to investigate a possible role of the highly conserved TM1 domain of $\operatorname{PrP}^{c}(\mathrm{i})$ in the cellular response to exogenous oxidative stress, (ii) in controlling endogenous ROS levels, and (iii) in modulation of mitochondrial membrane potential $(\Delta \Psi)$. We chose $\mathrm{N}_{2} \mathrm{~A}$ mouse neuroblastoma cells as an experimental system, as these cells have extensively been used in research on $\operatorname{PrP}^{c}$ and on prions. We transfected $\mathrm{N}_{2} \mathrm{~A}$ cells with expression constructs either encoding wild-type (wt) mouse $\operatorname{PrP}^{c}$ or with the deletion mutant PrPA114-121, carrying an 8-aa deletion in the TM1 region of $\operatorname{PrP}[10]$. In some of the experiments an expression plasmid encoding a PrP version lacking the octapeptide region was also used.

In order to assess cellular ROS levels we used $2^{\prime}, 7^{\prime}$-dichlorohydrofluorescein diacetate $\left(\mathrm{H}_{2}\right.$ DCFDA $)$ as a probe for quantitative analysis by flow cytometry (FACS) and tetramethylrhodamine ethyl ester perchlorate (TMRE) in order to monitor changes in $\Delta \Psi$.

\section{Experimental procedures}

\section{cDNA constructs}

The expression plasmid pL15TK [50] (empty vector, used for mock transfections) was the basis for creating pCMV-wtPrP [10] (henceforth termed wt-PrP) and pCMV- $\Delta 114-121 \operatorname{PrP}[10]$ (henceforth termed $\triangle 8$ TM1-PrP). Plasmid pcDNA3.1 $\triangle 43-91$ (henceforth termed $\triangle$ octaPrP) was described before [51]. Plasmids pCR3-Thy1 and pEGFP were used as controls.

\section{Cell culture}

The murine neuroblastoma cell line $\mathrm{N}_{2} \mathrm{~A}$ and its subclones ( $\mathrm{H} 6, \mathrm{H} 12$, D11, G9, and F1) were cultured as described [52]. The human cervical carcinoma cell line HeLa was cultured in DMEM (Gibco, Karlsruhe, Germany), 10\% FCS (Biochrom, Berlin, Germany), 1\% L-glutamine (Gibco), 1\% penicillin/streptomycin (Gibco). A Casy counter Model TT (Schärfe System, Reutlingen, Germany) was used for automated determination of cell numbers and cell viability.

\section{Transfection}

$\mathrm{N}_{2} \mathrm{~A}$ cells were transiently transfected using JetPEI reagent (Qbiogene, Illkirch, France) according to the manufacturer's instructions. Briefly $\mathrm{N}_{2} \mathrm{~A}$ were seeded in 24-well plates. The next day, transfections were performed. One microgram of DNA dissolved in $50 \mu \mathrm{l}$ of $150 \mathrm{mM} \mathrm{NaCl}$ was combined with $2 \mu \mathrm{l}$ JetPEI reagent prediluted in $50 \mu \mathrm{l}$ of $150 \mathrm{mM} \mathrm{NaCl}$. The mixture was incubated $30 \mathrm{~min}$ at RT and then added onto cells dropwise.

\section{Endogenous ROS and reaction to oxidative stress monitoring by FACS} analysis

The use of $\mathrm{H}_{2}$ DCFDA (Molecular Probes, Eugene, OR) as ROS staining and modified staining methods have been described by Sohn et al. [53] and Sauer et al. [54]. In order to set up the system, $\mathrm{H}_{2} \mathrm{O}_{2}$ (Merck, Darmstadt, Germany), tert-butylhydroperoxide (tBOOH) (Fluka, Munich, Germany), or the GSH-depleting compound buthionine sulfoximine (BSO) (Sigma, Munich, Germany) was applied, as indicated, to increase intracellular ROS levels. In subsequent experiments addressing the effect of transfected $\mathrm{PrP}$ versions, only $\mathrm{H}_{2} \mathrm{O}_{2}$ was used for the induction of oxidative stress. Briefly, 1 day posttransfection, medium was exchanged and cells were exposed or not to $100 \mu \mathrm{M}$ copper chloride hydrate $\left(\mathrm{CuCl}_{2}\right.$, Sigma) for 1 day. Then cells were washed with PBS $1 \times$ and fresh medium was added. Cells were then treated with $15 \mu \mathrm{M} 2^{\prime}, 7^{\prime}$ dichlorohydrofluorescein diacetate (Molecular Probes) in the presence or in absence of $3 \mathrm{mM}$ hydrogen peroxide $\left(\mathrm{H}_{2} \mathrm{O}_{2}\right.$, Merck, Darmstadt, Germany) for $30 \mathrm{~min}$. The cells were washed with PBS and trypsinized. Then $100 \mu \mathrm{l} \mathrm{FACS}$ buffer was added and FACScan analysis was performed using a FACScan flow (Beckton Dickson Biosciences, Mountain view, CA) equipped with Cell Quest version 3.3 software. Data analysis was performed using Flowjo 6.0 program (TreeStar, Asland, OR).

\section{Mitochondrial membrane potential monitoring by FACS analysis}

The use of TMRE (Sigma) as a probe for mitochondrial membrane potential has been described by Nicholls and Ward [55] and Scaduto et al. [56]. Briefly, 1 day posttransfection, medium was exchanged and cells were exposed or not to $100 \mu \mathrm{M}$ copper chloride hydrate $\left(\mathrm{CuCl}_{2}\right.$, Sigma) for 1 day. Then cells were washed with PBS $1 \times$ and fresh medium was added. Cells were treated with $4 \mu \mathrm{M}$ TMRE for $15 \mathrm{~min}$. Cells were washed with PBS, trypsinized, and resuspended in $100 \mu \mathrm{l}$ FACS buffer. Then FACScan analysis was performed.

\section{Statistics and normalization}

Each individual experiment was done at least in duplicates, and the mean values yielded the respective experimental data point of the day, to be used for further statistical analysis of the experiments performed independently on different days.

Crude data of transfected $\mathrm{N}_{2} \mathrm{~A}$ were normalized as follows: The mean values from all untreated mock samples were set to $100 \%$. All other data were expressed as percentage compared to the mock value of the same day. Student's $t$ test was performed on FACS results by using Analyse-It software (Analyse-it Software Ltd., Leeds, UK). $P<0.05$ was considered statistically significant. 


\section{Results}

In order to investigate the contribution of the TM1 domain of PrP to the physiological role(s) of this protein, $\mathrm{N}_{2} \mathrm{~A}$ cells were transfected with expression constructs for wt-PrP or $\triangle 8 \mathrm{TM} 1-\mathrm{PrP}$. The empty vector plasmid served as a control. In the transfected cultures, intracellular ROS levels in response to oxidative stress; endogenous ROS levels; and mitochondrial membrane potential $(\Delta \Psi)$ were assessed.
Endogenous ROS level after oxidant treatment of $N_{2} A, N_{2} A$ subclones, and HeLa cells

$\mathrm{H}_{2}$ DCFDA, which permits monitoring of the ROS level, was used as a probe, and its fluorescent intensity was measured by flow cytometry. In order to set up the system, gating of live cells and staining of unstressed cells with $\mathrm{H}_{2}$ DCFDA was performed (Fig. 1A). In addition, ROS levels in untransfected cells were measured with or without prior addition of $\mathrm{H}_{2} \mathrm{O}_{2}$, tert-butylhydroperoxide, or the GSH-depleting
A a)

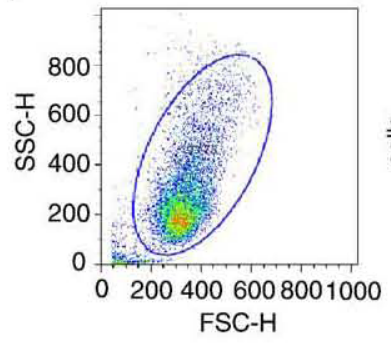

b)

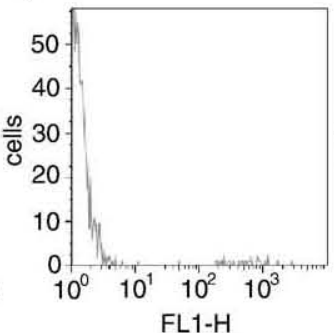

c)

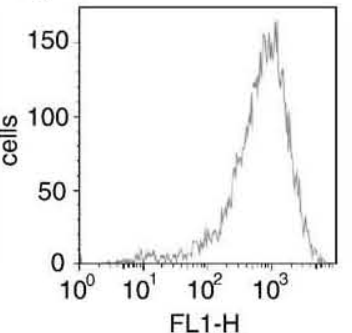

d)

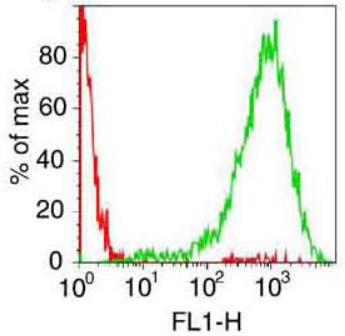

B a)

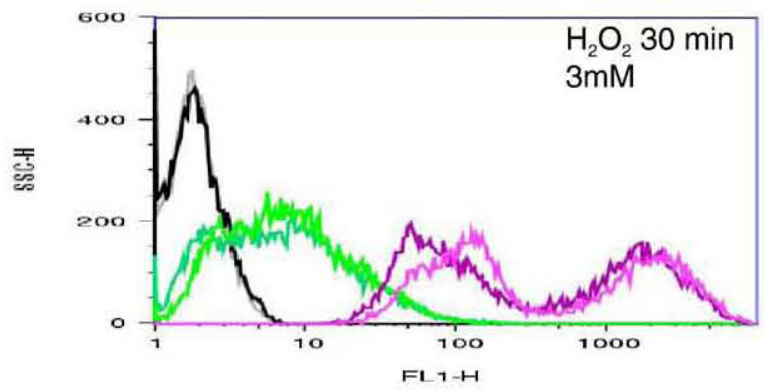

b)

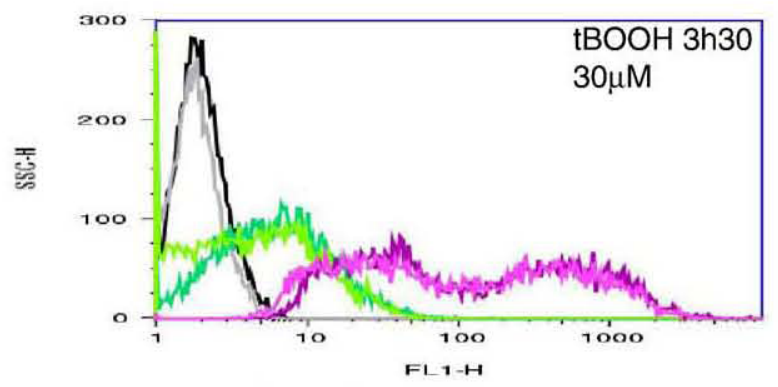

c)

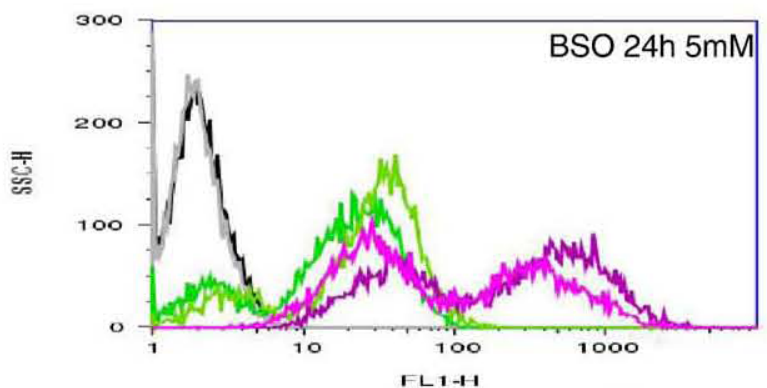

\section{H2DCFDAstaining \\ H2DCFDA staining + drug}

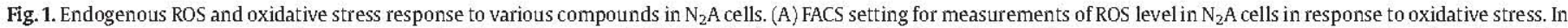

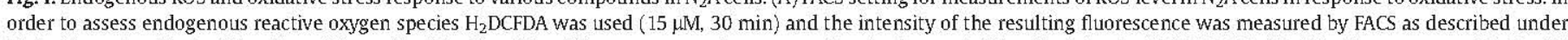

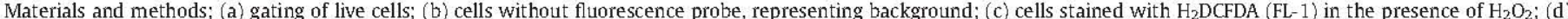

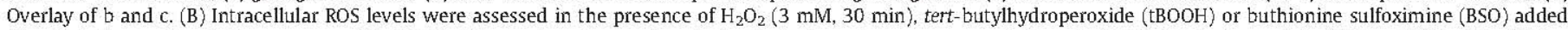

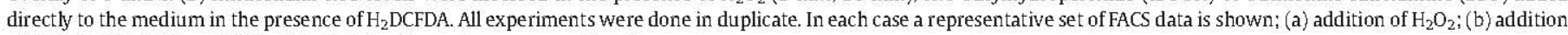
of $\mathrm{tBOOH}$; (c) addition of BSO. Note that double peaks are present in all cases. 
compound buthionine sulfoximine. In all three cases a similar shift to the right (i.e., increase of ROS) was observed (Fig. 1B), as expected, thus validating our readout system. All subsequent experiments were done with $\mathrm{H}_{2} \mathrm{O}_{2}$.

Further analyses on randomly picked subclones of $\mathrm{N}_{2} \mathrm{~A}$ [56] as well as on HeLa cells (human cervical carcinoma) revealed that the double peak observed in Fig. $1 \mathrm{~B}$ in the presence of $\mathrm{H}_{2}$ DCFDA and oxidants is due to some heterogeneity in the $\mathrm{N}_{2}$ A cell population. While HeLa cells showed a single peak (Fig. 2A), $\mathrm{N}_{2} \mathrm{~A}$ subclones (Figs. 2B-F) showed varying patterns. For the subsequent experiments $\mathrm{N}_{2} \mathrm{~A}$ mass cultures were used.

\section{A} HeLa

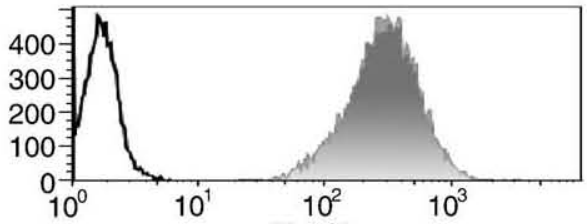

B

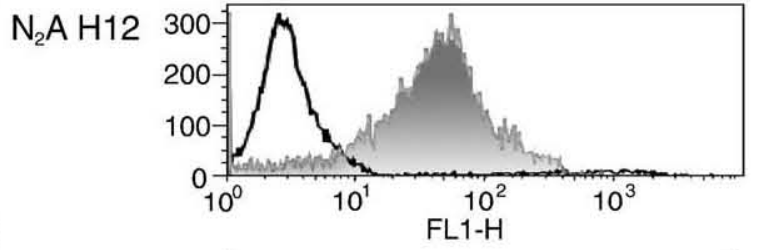

$\mathrm{N}_{2} \mathrm{~A}$ D11

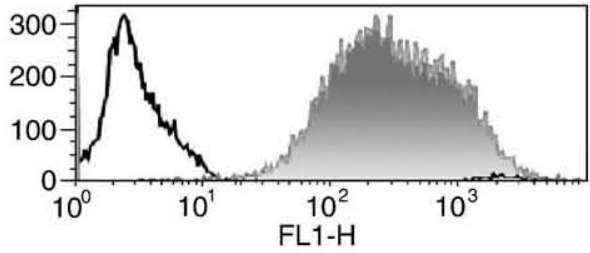

D $\mathrm{N}_{2} \mathrm{~A} \mathrm{H} 6$

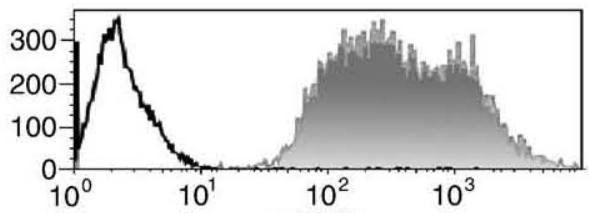

$\mathbf{E}_{\mathrm{N}_{2} \mathrm{~A}} \mathrm{~F} 1$

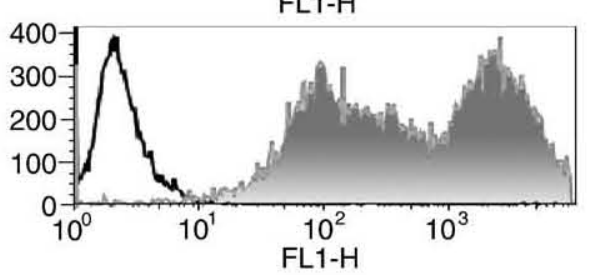

$\mathbf{F}$

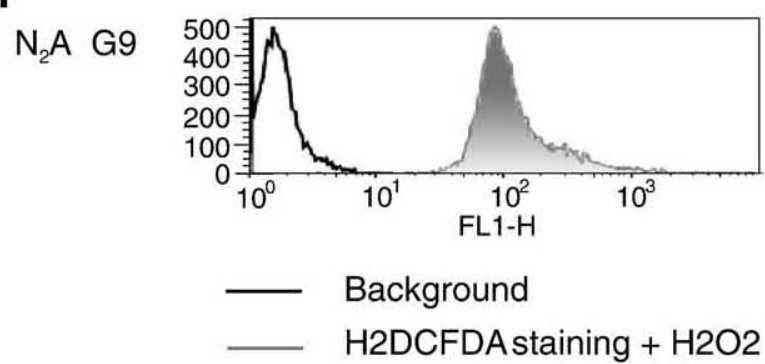

Fig. 2. Background and oxidative stress-induced DCF fluorescence in different cell populations. For each cells type a representative set of FACS data is shown. (A) HeLa; (B) $\mathrm{N}_{2}$ A subclone H12; (C) $\mathrm{N}_{2} A$ subclone D11; (D) $\mathrm{N}_{2} \mathrm{~A}$ subclone $\mathrm{H}$; (E) $\mathrm{N}_{2} \mathrm{~A}$ subclone $\mathrm{F} 1$; (F) $\mathrm{N}_{2} \mathrm{~A}$ subclone G9. Note the different patterns in the various cell populations.
Impact of overexpression of wt-PrP or $\triangle 8 T M 1-P r P$ on ROS levels in $N_{2} A$ cells exposed to exogenous hydrogen peroxide

As we performed transient transfections assays, a green fluorescent protein (GFP) construct was used to assess transfection efficiency. Routinely, about $60 \%$ of cells were GFP positive (data not shown). In addition, Western blots revealed very similar amounts of the various overexpressed PrP versions in transfected cells (Fig. S1).

In order to compare the impact of $\triangle 8 \mathrm{TM} 1-\mathrm{PrP}$ with wt-PrP on intracellular ROS levels under conditions of oxidative stress, cells were transfected with the respective PrP constructs and analyzed for ROS levels $24 \mathrm{~h}$ later. RoS levels were measured after exposure of the cells to $\mathrm{H}_{2} \mathrm{O}_{2}$ added directly to the medium in the presence of $\mathrm{H}_{2}$ DCFDA. Our data showed that ROS levels were significantly lower both in wt$\mathrm{PrP}$ and in $\triangle 8 \mathrm{TM} 1-\mathrm{Pr} P$-overexpressing cells compared to mock transfection (Figs. $3 \mathrm{~A}$ and $\mathrm{B}$ ), which indicates that both PrP versions exerted an antioxidant effect.

One possible explanation for such antioxidant effects could be a SOD-like activity of PrP or some change in upstream events controlling ROS levels. We therefore used a colorimetric test based on competition and xanthine/xanthine oxidase in $\mathrm{N}_{2} \mathrm{~A}$ cells overexpressing wt-PrP or $\triangle 8 \mathrm{TM} 1-\mathrm{PrP}$. No difference, however, was observed among mock, wtPrP, and $\triangle 8 T M 1-P r P-t r a n s f e c t e d$ cells in this system (data not shown), thus pointing to the relevance of other mechanisms.

Effect of copper treatment after oxidative stress in $\mathrm{N}_{2} \mathrm{~A}$ cells overexpressing wt-PrP, $\triangle 8 T M 1-P r$, or $\triangle$ octa-PrP

Because $\operatorname{Pr}^{c}$ can bind copper it was interesting to investigate the possible influence of copper on the oxidative stress response in $\mathrm{PrP}^{\mathrm{C}}$ overexpressing $\mathrm{N}_{2} \mathrm{~A}$ cells. Transfected $\mathrm{N}_{2} \mathrm{~A}$ cells were treated with copper $\left(100 \mu \mathrm{M} \mathrm{CuCl}_{2}\right)$ for 1 day followed by washing, fluorescent staining with $\mathrm{H}_{2}$ DCFDA, $\mathrm{H}_{2} \mathrm{O}_{2}$ exposure, and FACS analysis. The experiments were repeated independently and the results are expressed as a percentage of DCF intensity for mock-transfected cells in the absence of copper treatment (Fig. $3 \mathrm{C}$ ). The data show that, once again, the ROS level present in wt-PrP and $\triangle 8 \mathrm{TM} 1-\mathrm{PrP}$-overexpressing cells is significantly reduced compared to mock-transfected cells $(P=0.003$ and $P=0.04$, respectively). By contrast, cells overexpressing $\triangle$ octa-PrP did not show any change in ROS levels under these conditions.

After copper treatment the ROS level in mock-transfected cells showed only a tendency toward increase $(P=0.058)$. In wt-PrP and $\triangle 8 \mathrm{TM} 1-\mathrm{PrP}-$ overexpressing cells, however, copper treatment induced a significant increase of $\operatorname{ROS}(P=0.046$ for wt-PrP compared to mock; $P=0.012$ for the comparison between wt-PrP with and without copper treatment; $P=0.021$ for the comparison between $\triangle 8 \mathrm{TM} 1-\mathrm{Pr} P$ with and without copper treatment). By contrast, copper treatment had no significant effect on $\triangle$ octa-PrP-overexpressing cells.

\section{Effect of copper treatment on endogenous ROS levels in $\mathrm{N}_{2} A$ cells overexpressing wt-PrP, $\triangle 8 T M 1-P r P$, or $\triangle o c t a-P r P$}

In order to investigate the possible influence of overexpressing the above PrP versions on endogenous ROS in $\mathrm{N}_{2} \mathrm{~A}$ cells with or without copper treatment, the same experiments were performed in the absence of exogenous $\mathrm{H}_{2} \mathrm{O}_{2}$. Here, no statistically significant differences could be observed (Fig. 4B).

Effect of copper treatment on mitochondrial membrane potential in $\mathrm{N}_{2} \mathrm{~A}$ cells overexpressing wt-PrP, $\triangle 8 T M 1-\mathrm{PrP}$, or $\triangle$ octa-PrP

We also investigated the influence of copper on $\Delta \Psi$ in $N_{2} A$ cells overexpressing various $\operatorname{PrP}$ versions. Transfected $\mathrm{N}_{2} \mathrm{~A}$ cells were treated with copper for 1 day, followed by washing, fluorescent staining with TMRE, and FACS analysis. Our data revealed that copper treatment induced a significant decrease of $\Delta \Psi$ in mock, wt-PrP, 
A

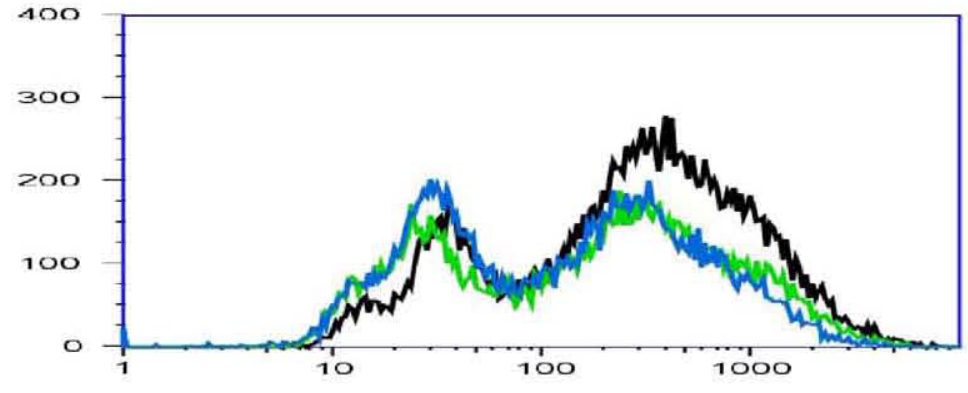

- Mock $\quad$ WT-PrP $\quad \Delta 8 \mathrm{TM} 1$

B Intensity of DCF

(\% of mock) $\quad \mathrm{N}=6$

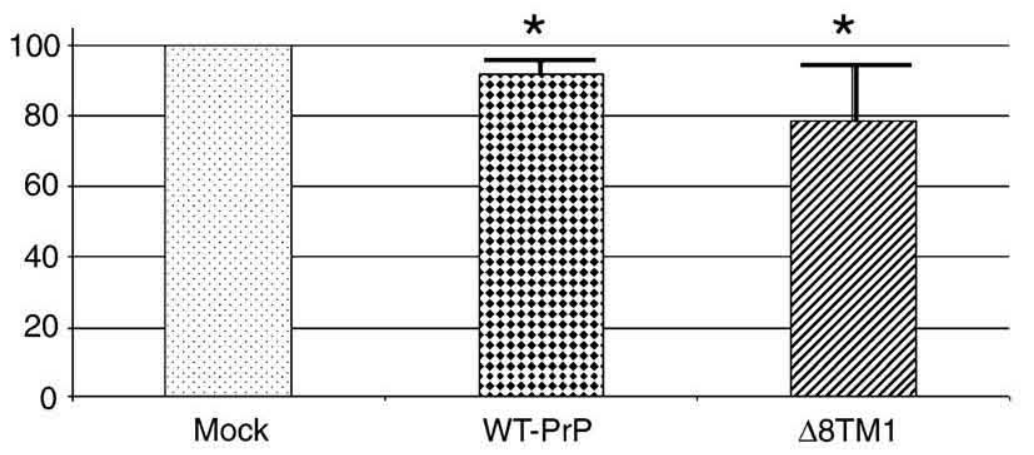

C Intensity of DCF

(\% of mock)

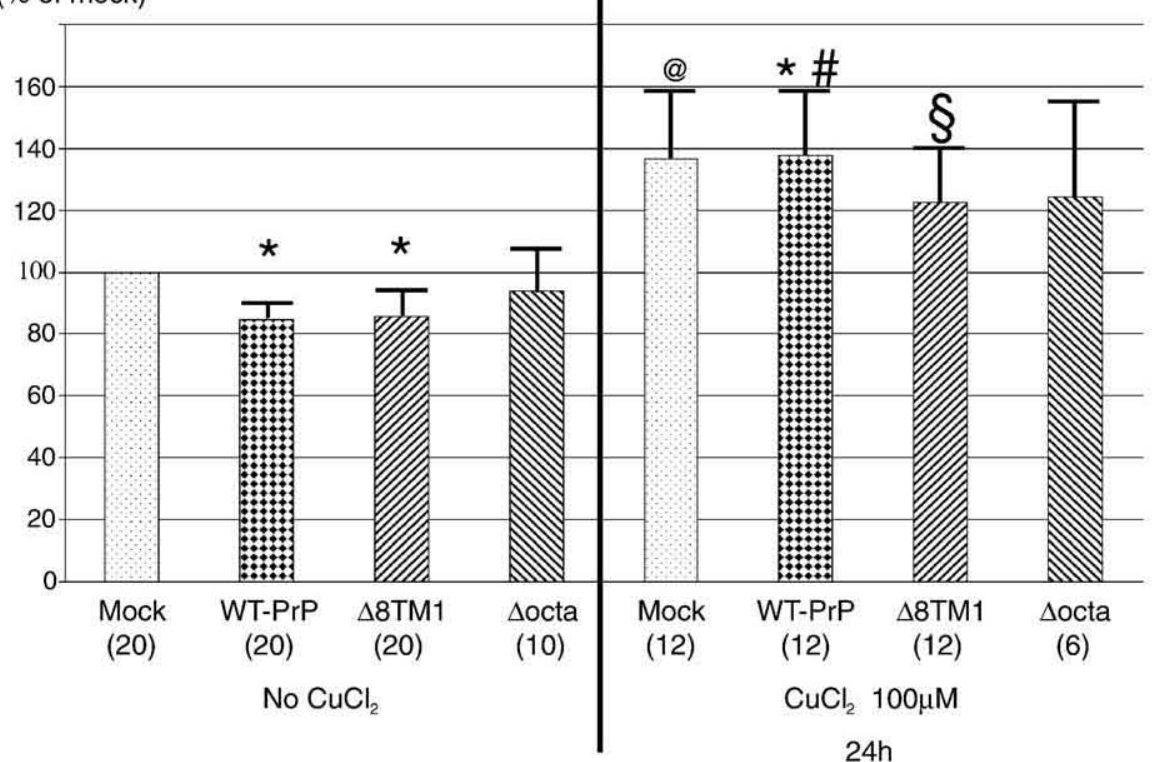

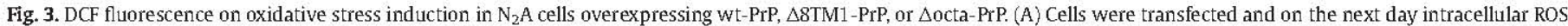

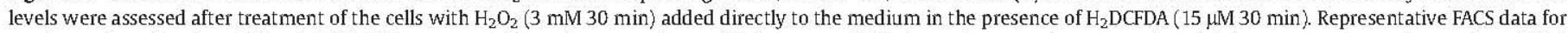

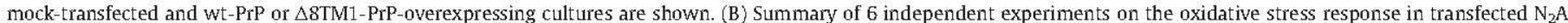

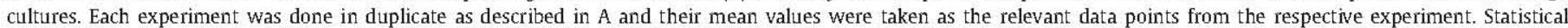

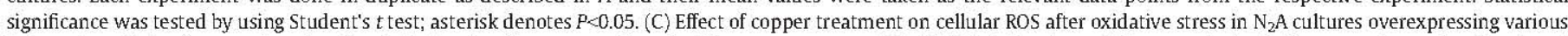

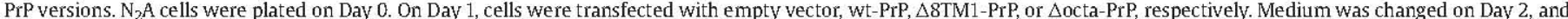

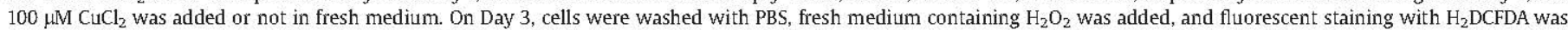

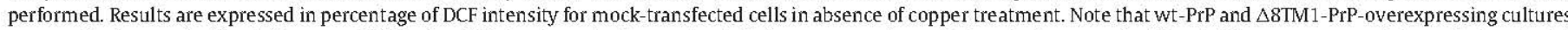

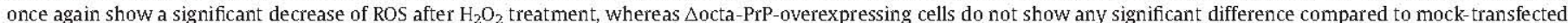

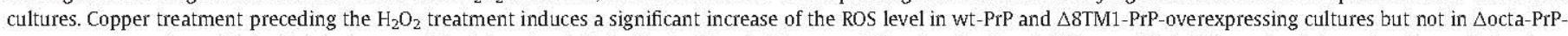

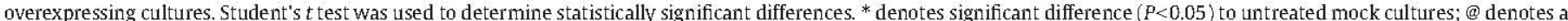

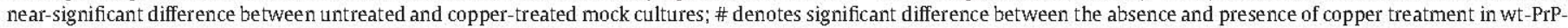

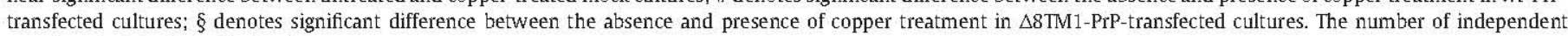
experiments is indicated in brackets. 
$A$ a)

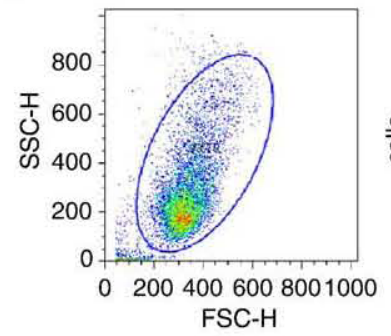

b)

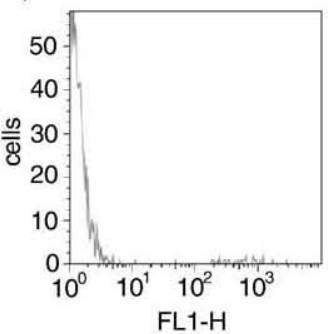

c)

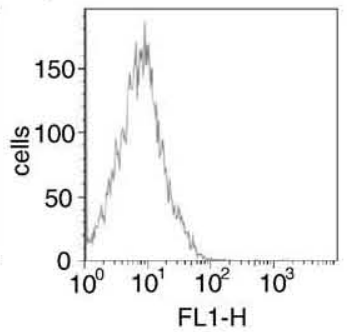

d)

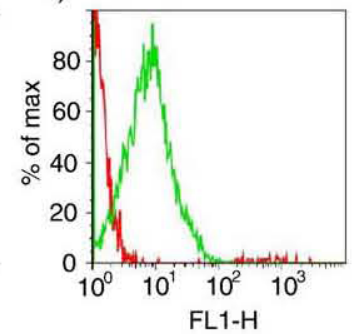

B

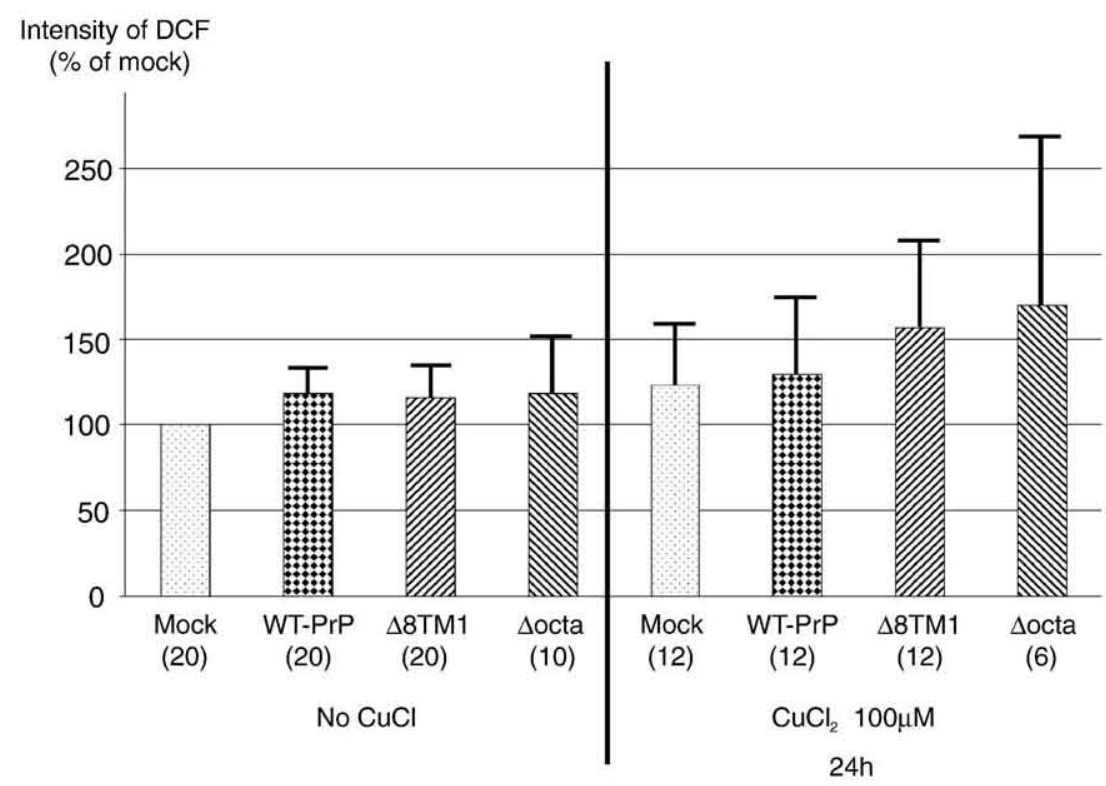

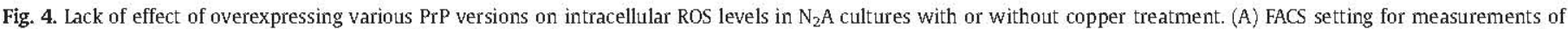

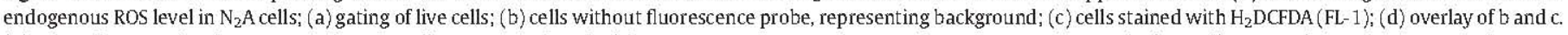

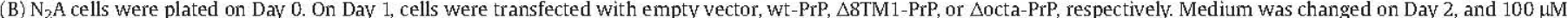

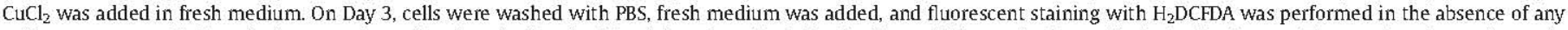

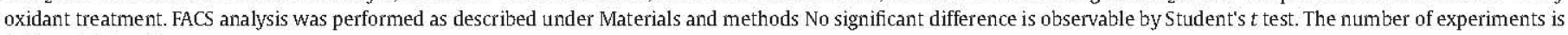
indicated in brackets.

$\triangle 8$ TM1-PrP, and $\triangle$ octa-PrP-transfected cells $(P=0.028$ for mock, $P=0.041$ for wt-PrP, $P=0.036$ for $\triangle 8$ TM1-PrP, and $P=0.027$ for $\triangle$ octaPrP compared to mock without copper treatment; Fig. 5B). A possible explanation for this reduction of $\Delta \Psi$ could be copper toxicity. However, neither microscopic inspection nor automated viability testing (Fig. 6) revealed any difference between any of the transfected cultures in the presence or absence of copper.

Interestingly $\Delta$ octa-PrP-overexpressing cells showed a $\Delta \Psi$ pattern different from that of mock-transfected cells, in that $\triangle$ octa-PrP overexpression significantly decreased $\Delta \Psi$ even without copper treatment compared to mock-transfected cells $(P=0.029)$.

In order to exclude any nonspecific effects due to overexpression of proteins carrying a GPI anchor, $\mathrm{N}_{2}$ A cells were transfected with a Thy- 1 expression construct. Thy- 1 is a GPI-anchored protein commonly used as a control for GPI-anchorage effects. Experiments to assess $\Delta \Psi$, endogenous ROS, and the reaction to oxidative stress experiments did not show any difference between mock and Thy-1-transfected cells (data not shown). Therefore the effects observed with wt-PrP, $\triangle 8$ TM1$\mathrm{PrP}$ and $\triangle$ octa-PrP apparently cannot be interpreted as a nonspecific consequence of overexpressing GPI-anchored proteins.

\section{Discussion}

In the present work, we studied the effects a partial deletion of the highly conserved transmembrane-1 (TM1) domain of $\operatorname{PrP}^{c}$ on the antioxidant effect of the protein. Our experimental strategy was to perform transient transfection assays in mouse $\mathrm{N}_{2}$ A neuroblastoma cells to study the effects of overexpression of the deletion mutant $\triangle 8 \mathrm{TM1}$ $\mathrm{PrP}$, in comparison with wild-type $\operatorname{Pr}^{c}$, on intracellular RoS levels. We did this under both basal and oxidative stress conditions. Since $\operatorname{Pr}^{c}$ can bind copper ions and this transition metal plays important roles both in oxidative stress induction and in ROS detoxification, the experiments were performed with or without pretreatment with exogenously added copper, respectively. For the same reason we also included in some of the experiments $\triangle$ octa-PrP, a mutant with a deletion of the octarepeat region, where much of the copper binding occurs. Finally we monitored $\Delta \Psi$ in the transfected cultures in the presence or absence of copper.

We opted for using transient transfections rather than establishing stably transfected cells, which has a major advantage of avoiding the risk of artifacts based on clonal effects. On the other hand only a proportion of the cells in the transfected culture are reached, in our case about $60 \%$ as assessed with a GFP expression plasmid. As revealed by Western blots, the overall level of expression of the transfected PrP versions was comparable (Fig. S1). It is important to note that expression of the transfected gene only in about two-thirds of the cell population only will, of course, diminish the apparent biological effect of the transgene (i.e., inhibition of ROS formation) in the total population of cells analyzed by flow cytometry. This is reflected by the rather low amplitude of the statistically significant effects described in this paper. 
A a)

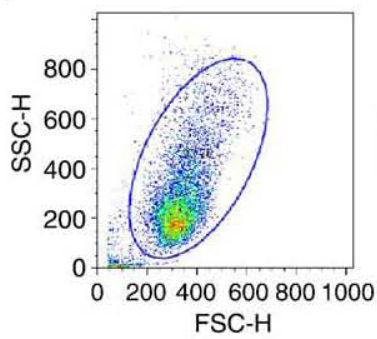

B b)

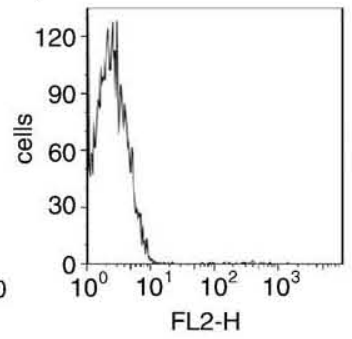

c)

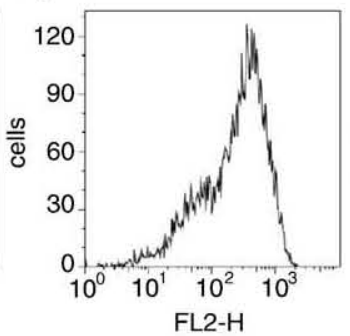

d)

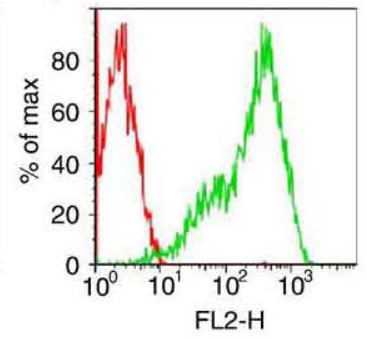

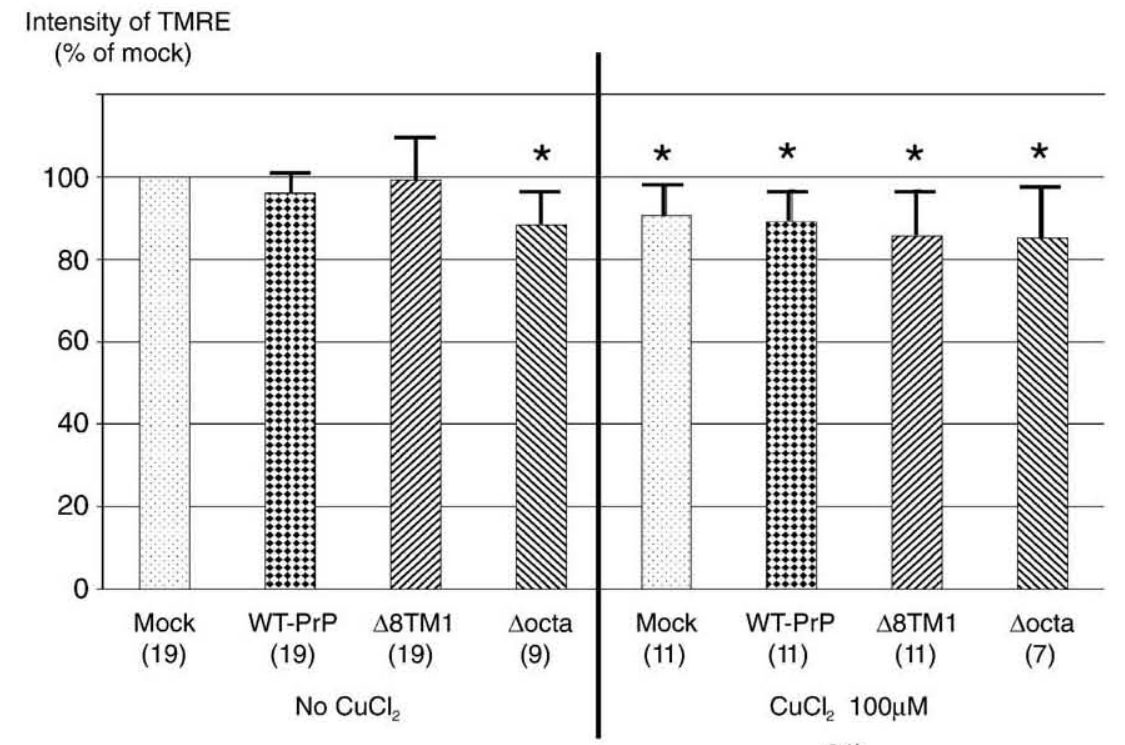

$24 \mathrm{~h}$

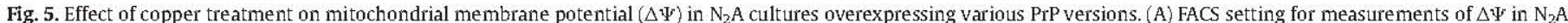

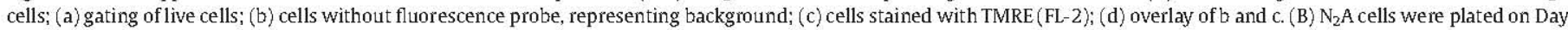

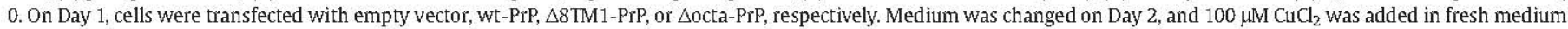

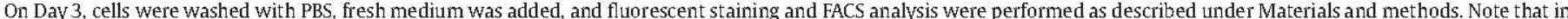

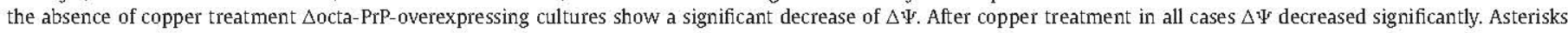
represent statistically significant differences $(P<0.05)$ compared with untreated mock-transfected cultures. The number of independent experiments is indicated in brackets.

Our data showed a significant decrease of intracellular ROS levels after oxidative stress in cells overexpressing either wt-PrP or $\triangle 8 \mathrm{TM} 1-$ $\operatorname{PrP}$ (Figs. 3A and B). While an antioxidant role of wt-PrP $\mathrm{P}^{c}$ has already been described, our results provide new information for $\triangle 8 \mathrm{TM} 1-\mathrm{Pr}$. By contrast, we observed no significant protective effect in $\Delta$ octa-PrPoverexpressing cultures, in perfect agreement with previously published data [57]. Interestingly a very recent publication described the antioxidant protection of human SH-SY5Y neuroblastoma cells against toxicity of the oxidant agent paraquat by overexpression of wt$\operatorname{PrP}^{c}$ but not $\triangle$ octa-PrP [58]. The parameters measured were cell viability, loss of membrane integrity, and mitochondrial bioenergetics. While these authors used a different cellular system, a different oxidant agent and different biological readouts, these data and our own data shown here on $\triangle$ octa-PrP are fully compatible and complementary.

The protective effect of wt-PrP or $\Delta 8 \mathrm{TM} 1-\mathrm{PrP}$ overexpression was apparently lost after copper pretreatment followed by exposure to $\mathrm{H}_{2} \mathrm{O}_{2}$. This may be due to some generally increased biological variation of our results obtained after copper treatment (Fig. 3C). A possible explanation for the latter observation is the fact that $\mathrm{H}_{2} \mathrm{O}_{2}$ exposure of cells preloaded with copper is likely to elicit the formation of large amounts of hydroxyl radicals through the interaction of $\mathrm{H}_{2} \mathrm{O}_{2}$ and copper, enabling Fenton chemistry. This notion is fully consistent with the increased DCF signal observed in all cases of copper pretreatment combined with $\mathrm{H}_{2} \mathrm{O}_{2}$ challenge (Fig. $3 \mathrm{C}$ ). Small differences in the uptake of one or both interaction partners, i.e., copper and/or $\mathrm{H}_{2} \mathrm{O}_{2}$, or their intracellular metabolism may therefore well translate into the

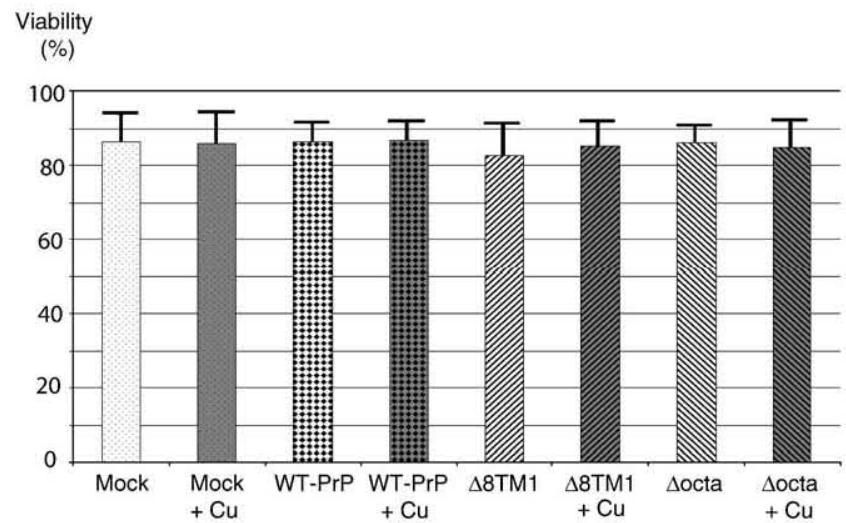

Fig. 6. Viability after copper treatment of $\mathrm{N}_{2} \mathrm{~A}$ cultures overexpressing various $\operatorname{Pr} P$ versions. The cell treatment protocol was identical to that used for FACS analysis except for the addition of the fluorescence probe. Instead, cells were analyzed in a Casy cell counter. Four independent experiments were performed. Statistical analysis by Student's $t$ test revealed no significant difference among any of the conditions. 
larger biological variation of intracellular ROS formation apparent in Fig. 3C.

A possible explanation for PrP's protective effect against oxidative stress (Figs. 3A and B) could be some SOD-like activity, as proposed by Brown and colleagues $[25,26]$. In our system, however, no enhanced SOD activity was detected in wt-PrP or $\triangle 8 \mathrm{TM} 1-\mathrm{PrP}$-transfected $\mathrm{N}_{2} \mathrm{~A}$ (data not shown), in agreement with data from the literature [27].

Interestingly, overexpression of wt-PrP, $\triangle 8 \mathrm{TM} 1-\mathrm{PrP}$, or $\triangle$ octa-PrP did not decrease basal ROS levels (Fig. 4B). Furthermore, copper treatment had no impact on the basal ROS level in cultures overexpressing any of the three PrP versions (Fig. 4B). Viewed together with the antioxidant effect of $\operatorname{PrP}^{c}$ under conditions of oxidative stress this observation points to some role of the protein in the acute signaling of oxidative stress, rather than a constitutive antioxidant function.

Because of the close relationship between ROS formation and the mitochondrial respiratory chain [59], we compared $\Delta \Psi$ in mocktransfected cultures with that of PrP-wt, $\Delta 8 \mathrm{TM} 1$, or $\Delta$ octa-overexpressing cultures (Fig. 5B). Neither wt-PrP nor $\triangle 8 \mathrm{TM} 1-\mathrm{Pr}$ - - -overexpressing cultures showed any alteration in $\Delta \Psi$ compared to mocktransfected cultures. By contrast $\Delta$ octa-PrP-transfected cells showed a statistically significant decrease of $\Delta \Psi$. In all cases, $\Delta \Psi$ decreased significantly after copper treatment, which was apparently not due to copper-induced cytotoxicity (Fig. 6).

The decrease of $\Delta \Psi$ in $\Delta$ octa-PrP-transfected cultures is a novel and unexpected finding. The underlying mechanisms are unknown, and it will be interesting to follow these up in future work. For the interpretation of the present data, however, it is clear that this decrease of $\Delta \Psi$ did not translate into lower levels of basal (Fig. 4B) or oxidative stress-induced ROS (Fig. 3C), as one might have presumed.

In summary, the protective effect of $\operatorname{PrP}^{\mathrm{C}}$ against oxidative stress involves the octarepeat region but not the highly conserved TM1 domain nor the high-affinity copper binding site at human residues His96/His 111 (corresponding to murine residues 95/110), which are both present in the $\triangle$ octa-PrP mutant. While it is attractive to hypothesize that the primordial physiological function of $\operatorname{Pr}^{c}$ is in antioxidant defense, this view is not supported by our present data showing that the most highly conserved region of $\operatorname{Pr}^{c}$ is apparently not involved in this function. Therefore other known or suspected functions of $\operatorname{PrP}^{c}$ deserve increased scrutiny.

\section{Acknowledgments}

We thank Prof. Marcus Groettrup and Dr. Daniel Legler (Chair of Immunology, Department of Biology, University of Konstanz, D-78457 Konstanz, Germany) for helpful advice on and access to flow cytometry. We gratefully acknowledge funding by the Deutsche Forschungsgemeinschaft through the "TransRegio-SFB 11 KonstanzZürich, Structure and Function of Membrane Proteins" (TP C10) as well as funding by the EU Commission through the FP6 Network of Excellence "NeuroPrion"/subproject PrioGen.

\section{Appendix A. Supplementary data}

Supplementary data associated with this article can be found, in the online version, at doi:10.1016/j.freeradbiomed.2008.08.024.

\section{References}

[1] Silveira, J. R.; Caughey, B.; Baron, G. S. Prion protein and the molecular features of transmissible spongiform encephalopathy agents. Curr. Top. Microbiol. Immunol 284:1-50; 2004

[2] McKintosh, E.; Tabrizi, S. J.; Collinge, J. Prion diseases. J. Neurovirol. 9:183-193; 2003.

[3] Budka, H. Neuropathology of prion diseases. Br. Med. Bull. 66:121-130; 2003.

[4] Basler, K.; Oesch, B.; Scott, M.; Westaway, D.; Walchli, M.; Groth, D. F.; McKinley, M. P.; Prusiner, S. B.; Weissmann, C. Scrapie and cellular PrP isoforms are encoded by the same chromosomal gene. Cell 46:417-428; 1986.
5] Sparkes, R. S.; Simon, M.; Cohn, V. H.; Fournier, R. E.; Lem, J.; Klisak, I.; Heinzmann, C.; Blatt, C.; Lucero, M.; Mohandas, T., et al. Assignment of the human and mouse prion protein genes to homologous chromosomes. Proc. Nati. Acad. Sci. USA 83:7358-7362; 1986.

[6] Simonic, T.; Duga, S.; Strumbo, B.; Asselta, R.; Ceciliani, F.; Ronchi, S. cDNA cloning of turtle prion protein. FEBS Lett. 469:33-38; 2000.

[7] Wopfner, F.; Weidenhofer, G.; Schneider, R; von Brunn, A.; Gilch, S.; Schwarz, T. F.; Werner, T.; Schatzl, H. M. Analysis of 27 mammalian and 9 avian PrPs reveals high conservation of flexible regions of the prion protein. J. Mol. Biol. 289:1163-1178; 1999

8] Rivera-Milla, E.; Oidtmann, B.; Panagiotidis, C. H.; Baier, M.; Sklaviadis, T.; Hoffmann, R.; Zhou, Y.; Solis, G. P.: Stuermer, C. A.; Malaga-Trillo, E. Disparate evolution of prion protein domains and the distinct origin of Doppel- and prionrelated loci revealed by fish-to-mammal comparisons. FASEB J. 20:317-319; 2006.

[9] Zahn, R.; Liu, A.; Luhrs, T.; Riek, R.; von Schroetter, C; Lopez Garcia, F.; Billeter, M.; Calzolai, L.; Wider, G.; Wuthrich, K. NMR solution structure of the human prion protein. Proc. Nati. Acad. Sci. USA 97:145-150; 2000.

[10] Holscher, C. Delius, H.; Bürkle, A. Overexpression of nonconvertible PrPC delta114-121 in scrapie-infected mouse neuroblastoma cells leads to transdominant inhibition of wild-type $\operatorname{PrP}(\mathrm{Sc})$ accumulation. J. Virol. 72:1153-1159; 1998.

[11] Baumann, F.; Tolnay, M.; Brabeck, C; Pahnke, J.; Kloz, U.; Niemann, H. H.; Heikenwalder, M.; Rulicke, T.; Bürkle, A.; Aguzzi, A. Lethal recessive myelin toxicity of prion protein lacking its central domain. EMBO I. 26:538-547; 2007.

[12] Krebs, B.; Dorner-Ciossek, C.; Schmalzbauer, R.; Vassallo, N.; Herms, J.: Kretzschmar, H. A. Prion protein induced signaling cascades in monocytes. Biochem. Biophys. Res. Commun. 340:13-22; 2006.

[13] de Almeida, C. J.; Chiarini, L. B.; da Silva, J. P.; e Silva, P. M.; Martins, M. A.; Linden, R. The cellular prion protein modulates phagocytosis and inflammatory response. I. Leukoc. Biol. 77:238-246; 2005

[14] Mouillet-Richard, S.; Ermonval, M.; Chebassier, C.; Laplanche, J. L.; Lehmann, S.; Launay, J. M.; Kellermann, O. Signal transduction through prion protein. Science 289:1925-1928; 2000

[15] Schneider, B.; Mutel, V.; Pietri, M.; Ermonval, M.; Mouillet-Richard, S.; Kellermann, 0 . NADPH oxidase and extracellular regulated kinases $1 / 2$ are targets of prion protein signaling in neuronal and nonneuronal cells. Proc. Nati. Acad. Sci. USA 100:13326-13331; 2003.

[16] Spielhaupter, C.; Schatzl, H. M. PrPC directly interacts with proteins involved in signaling pathways. I. Biol. Chem. 276:44604-44612; 2001.

[17] Brown, D. R.; Qin, K.; Herms, J. W.; Madlung, A; Manson, J.; Strome, R.; Fraser, P. E.; Kruck, T.; von Bohlen, A.; Schulz-Schaeffer, W.; Giese, A.; Westaway, D.; Kretzschmar, $\mathrm{H}$. The cellular prion protein binds copper in vivo. Nature 390:684-687; 1997

[18] Burns, C. S.; Aronoff-Spencer, E.; Legname, G.; Prusiner, S. B.; Antholine, W. E.; Gerfen, G. J.; Peisach, J.; Millhauser, G. L. Copper coordination in the full-length, recombinant prion protein. Biochemistry 42:6794-6803; 2003.

[19] Chattopadhyay, M.; Walter, E. D.; Newell, D. J.; Jackson, P. J.; Aronoff-Spencer, E.; Peisach, J.; Gerfen, G. J.; Bennett, B.; Antholine, W. E.; Millhauser, G. L. The octarepeat domain of the prion protein binds $\mathrm{Cu}$ (II) with three distinct coordination modes at pH 7.4. J. Am. Chem. Soc. 127:12647-12656; 2005.

[20] Millhauser, G. L. Copper binding in the prion protein. Acc. Chem. Res, 37:79-85; 2004

[21] Collinge, J.; Whittington, M. A.; Sidle, K. C.; Smith, C. J.; Palmer, M. S.; Clarke, A. R.; Jefferys, J. G. Prion protein is necessary for normal synaptic function. Nature 370:295-297; 1994.

[22] Gains, M. J.; Roth, K. A.; LeBlanc, A. C. Prion protein protects against ethanolinduced Bax-mediated cell death in vivo. Neuroreport 17:903-906; 2006

[23] Kristiansen, M.; Messenger, M. J.; Klohn, P. C.; Brandner, S.; Wadsworth, J. D.; Collinge, J.; Tabrizi, S. J. Disease-related prion protein forms aggresomes in neuronal cells leading to caspase activation and apoptosis. 1 . Biol. Chem. 280:38851-38861; 2005

[24] Roucou, X.; Giannopoulos, P. N.; Zhang, Y.; Jodoin, J.; Goodyer, C. G.; LeBlanc, A. Cellular prion protein inhibits proapoptotic Bax conformational change in human neurons and in breast carcinoma MCF-7 cells. Cell Death Differ. 12:783-795; 2005

[25] Brown, D. R.; Besinger, A. Prion protein expression and superoxide dismutase activity. Biochem. I. 334 (Pt 2):423-429; 1998.

[26] Brown, D. R.; Wong, B. S.; Hafiz, F.; Clive, C.; Haswell, S. J.; Jones, I. M. Normal prion protein has an activity like that of superoxide dismutase. Biochem. J. 344 (Pt 1):1-5; 1999.

[27] Hutter, G.; Heppner, F. L.; Aguzzi, A. No superoxide dismutase activity of cellular prion protein in vivo. Biol. Chem. 384:1279-1285; 2003.

[28] Brown, D. R. Prion and prejudice: normal protein and the synapse. Trends Neurosci. 24:85-90; 2001.

[29] Rachidi, W.; Vilette, D.; Guiraud, P.; Arlotto, M.; Riondel, J.; Laude, H.; Lehmann, S.; Favier, A. Expression of prion protein increases cellular copper binding and antioxidant enzyme activities but not copper delivery. J. Biol. Chem. 278:9064-9072; 2003.

[30] Jones, C. E.; Abdelraheim, S. R.; Brown, D. R.; Viles, J. H. Preferential $\mathrm{Cu}^{2+}$ coordination by His96 and His 111 induces beta-sheet formation in the unstructured amyloidogenic region of the prion protein. J. Biol Chem. 279:32018-32027; 2004.

[31] Thompsett, A. R.; Abdelraheim, S. R.; Daniels, M.; Brown, D. R. High affinity binding between copper and full-length prion protein identified by two different techniques. J. Biol. Chem. 280:42750-42758; 2005. 
[32] Brown, D. R.; Schulz-Schaeffer, W. J.; Schmidt, B.; Kretzschmar, H. A. Prion proteindeficient cells show altered response to oxidative stress due to decreased SOD-1 activity. Exp. Neurol. 146:104-112; 1997.

[33] Klamt, F.; Dal-Pizzol, F.; Conte da Frota, M. J.; Walz, R.; Andrades, M. E.; da Silva, E. G.; Brentani, R. R.; Izquierdo, I.; Fonseca Moreira, J. C. Imbalance of antioxidant defense in mice lacking cellular prion protein. Free Radic. Biol. Med. 30:1137-1144; 2001.

[34] White, A. R: Collins, S. J: Maher, F: Jobling M. F: Stewart, L. R.; Thyer, J. M: Beyreuther, K.; Masters, C. L; Cappai, R. Prion protein-deficient neurons reveal lower glutathione reductase activity and increased susceptibility to hydrogen peroxide toxicity. Am. J. Pathol 155:1723-1730; 1999.

[35] Brown, D. R.; Clive, C.; Haswell, S. J. Antioxidant activity related to copper binding of native prion protein. J. Neurochem. 76:69-76; 2001

[36] Sakudo, A.; Lee, D. C; Li, S.; Nakamura, T.; Matsumoto, Y.; Saeki, K.; Itohara, S.; Ikuta, K.; Onodera, T. PrP cooperates with STI1 to regulate SOD activity in PrPdeficient neuronal cell line. Biochem. Biophys. Res. Commun. 328:14-19; 2005.

[37] Weise, J.; Crome, O.; Sandau, R.; Schulz-Schaeffer, W.; Bahr, M.; Zerr, I. Upregulation of cellular prion protein $(\mathrm{PrPc})$ after focal cerebral ischemia and influence of lesion severity. Neurosci. Lett. 372:146-150; 2004.

[38] Shyu, W. C.; Lin, S. Z.; Chiang, M. F; Ding, D. C.; Li, K. W.; Chen, S. F.; Yang, H. I.; Li, H. Overexpression of PrPC by adenovirus-mediated gene targeting reduces ischemic injury in a stroke rat model. J. Neurosci. 25:8967-8977; 2005.

[39] Spudich, A.; Frigg, R.; Kilic, E.; Kilic, U.; Oesch, B.; Raeber, A.; Bassetti, C. L.; Hermann, D. M. Aggravation of ischemic brain injury by prion protein deficiency: role of ERK-1/-2 and STAT-1. Neurobiol. Dis. 20:442-449; 2005.

[40] Weise, J.; Sandau, R.; Schwarting, S.; Crome, O.; Wrede, A.; Schulz-Schaeffer, W.; Zerr, I.; Bahr, M. Deletion of cellular prion protein results in reduced Akt activation, enhanced postischemic caspase- 3 activation, and exacerbation of ischemic brain injury. Stroke 37:1296-1300; 2006

[41] Mitsios, N.; Saka, M.; Krupinski, J.; Pennucci, R.; Sanfeliu, C.; Miguel Turu, M.; Gaffney, J.; Kumar, P.; Kumar, S.; Sullivan, M.; Slevin, M. Cellular prion protein is increased in the plasma and peri-infarcted brain tissue after acute stroke. J. Neurosci Res. 85:602-611; 2007.

[42] Milhavet, 0.; Lehmann, S. Oxidative stress and the prion protein in transmissible spongiform encephalopathies. Brain Res. Brain Res. Rev. 38:328-339; 2002.

[43] Simonian, N. A.; Coyle, J. T. Oxidative stress in neurodegenerative diseases. Annu. Rev. Pharmacol Toxicol 36:83-106; 1996.

[44] Sayre, L. M.; Perry, G.; Smith, M. A. Redox metals and neurodegenerative disease. Curr. Opin. Chem. Biol. 3:220-225; 1999.

[45] Smaili, S. S.; Hsu, Y. T.; Youle, R. J.; Russell, J. T. Mitochondria in $\mathrm{Ca}^{2+}$ signaling and apoptosis. J. Bioenerg. Biomembr. 32:35-46; 2000.

[46] Smaili, S. S.; Hsu, Y. T.; Carvalho, A. C; Rosenstock, T. R.; Sharpe, J. C; Youle, R. J. Mitochondria, calcium and pro-apoptotic proteins as mediators in cell death signaling. Braz. J. Med. Biol. Res. 36:183-190; 2003.
[47] Lobão-Soares, B.; Bianchin, M. M.; Linhares, M. N.: Carqueja, C. L.; Tasca, C. I.; Souza, M.; Marques Jr, W.; Brentani, R; Martins, V. R.; Sakamoto, A. C.; Carlotti Jr C. G.; Walz, R. Normal brain mitochondrial respiration in adult mice lacking cellular prion protein. Neurosci. Lett. 375:203-206; 2005.

[48] Nico, P. B.; Lobão-Soares, B.; Landemberger, M. C.; Marques Jr, W.; Tasca, C. I de Mello, C. F.; Walz, R.; Carlotti Jr, C. G.; Brentani, R. R.; Sakamoto, A. C.; Bianchin, M. M. Impaired exercise capacity, but unaltered mitochondrial respiration in skeletal or cardiac muscle of mice lacking cellular prion protein. Neurosci. Lett 388:21-26; 2005.

[49] Paterson, A. W.; Curtis, J. C.; Macleod, N. K. Complex I specific increase in superoxide formation and respiration rate by $\mathrm{PrP}$-null mouse brain mitochondria. I. Neurochem 105:177-191; 2008

[50] Küpper, J. H.; de Murcia, G.; Bürkle, A. Inhibition of poly(ADP-ribosyl)ation by overexpressing the poly(ADP-ribose) polymerase DNA-binding domain in mammalian cells. J. Biol. Chem. 265:18721-18724; 1990.

[51] Gilch, S.; Nunziante, M.; Ertmer, A.; Wopfner, F; Laszlo, L.; Schatzl, H. M Recognition of lumenal prion protein aggregates by post-ER quality control mechanisms is mediated by the preoctarepeat region of PrP. Traffic 5:300-313 2004.

[52] Zhang, Y.; Poirier, G. G.; Bürkle, A. In-situ analysis of cellular poly(ADP-ribose) production in scrapie-infected mouse neuroblastoma cells. Histochem. $J$ 34:357-363; 2002

[53] Sohn, I. P.; Ahn, H. J.; Park, D. W.; Gye, M. C; Jo do, H.; Kim, S. Y.; Min, C. K.; Kwon, H. C. Amelioration of mitochondrial dysfunction and apoptosis of two-cell mouse embryos after freezing and thawing by the high frequency liquid nitrogen infusion. Mol. Cells 13:272-280; 2002.

[54] Sauer, H.; Wefer, K.; Vetrugno, V.; Pocchiari, M.; Gissel, C.; Sachinidis, A. Hescheler, J.; Wartenberg, M. Regulation of intrinsic prion protein by growth factors and TNF-alpha: the role of intracellular reactive oxygen species. Free Radic Biol. Med. 35:586-594; 2003.

[55] Nicholls, D. G.; Ward, M. W. Mitochondrial membrane potential and neuronal glutamate excitotoxicity: mortality and millivolts. Trends Neurosci. 23:166-174; 2000 .

[56] Scaduto, R. C., Jr.; Grotyohann, L. W. Measurement of mitochondrial membrane potential using fluorescent rhodamine derivatives. Biophys. J. 76:469-477; 1999.

57] Watt, N. T: Taylor, D. R. Gillott, A. Thomas, D. A.; Perera, W. S.; Hooper, N. M. Reactive oxygen species-mediated beta-cleavage of the prion protein in the cellular response to oxidative stress. J. Biol Chem. 280:35914-35921; 2005.

[58] Dupiereux, I.; Falisse-Poirrier, N.; Zorzi, W.; Watt, N. T.; Thellin, O.; Zorzi, D. Pierard, O.; Hooper, N. M.; Heinen, E.; Elmoualij, B. Protective effect of prion protein via the $\mathrm{N}$-terminal region in mediating a protective effect on paraquatinduced oxidative injury in neuronal cells. $J$. Neurosci. Res. 86:653-659; 2008.

[59] Kowaltowski, A. J.; Vercesi, A. E. Mitochondrial damage induced by conditions of oxidative stress. Free Radic. Biol. Med. 26:463-471; 1999. 